DOI 10.37882/2223-2982.2021.06.26

\title{
СПОСОБЫ ПЕРЕДАЧИ ЛИНГВОКУЛЬТУРНОГО КОМПОНЕНТА ПРИ ПЕРЕВОДЕ АНГЛИЙСКИХ СКАЗОК НА РУССКИЙ ЯЗЫК
}

\section{WAYS OF CONVEYING CULTURAL LINGUISTIC COMPONENTS OF ENGLISH FAIRY TALES IN THEIR RUSSIAN TRANSLATION}

\section{E. Leonova}

I. Girina

Summary: The article studies the ways of conveying linguocultural features of an English fairy tale in its Russian translation. The linguistic worldview of people reflects their cultural worldview, while cultural characteristics of people are reflected in the texts created by them. The linguocultural features of the text under study include mythologized linguistic units, symbols, non-equivalent vocabulary, and stylistic features of languages. When the translation is analyzed, special attention is paid to local dialect, vernacular language, euphemisms, taking into account differences in the meaning of lexical units, as well as the choice of a translation strategy.

Keywords: linguoculture, symbol, euphemism, vernacular language, translation strategy.

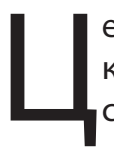
елью данного исследования является лингвокультурологический анализ перевода английской сказки Том Тит Тот (Tom Tit Tot).

В сегодняшний век глобализации, когда стираются границы в плане сотрудничества различных государств, в век интернета и соцсетей происходит размывание культурных границ между представителями различных национальностей. Происходит поглощение маленьких народов и стирание их культурной самобытности, забывание родного языка и национальных корней. Вместе с этим происходит и другая тенденция - стремление сохранить свои национальные корни, свою культуру. Так, современный исследователь Э. Вольф подвергает сомнению само понятие культуры, утверждая, что каждая культура не есть самостоятельная монада и что все культуры взаимосвязаны и постоянно перетекают одна в другую, при этом некоторые из них сильно видоизменяются, а некоторые прекращают свое существование. [1; с.15] Первоначальное определение культуры в научной литературе принадлежит Э. Тайлору, который понимал культуру как комплекс, включающий знания, верования, искусства, законы, мораль, обычаи и другие способности и привычки, обретенные человеком как членом общества. Наряду со сложностью и многоаспектностью В.А. Маслова выделяет такое свойство культуры
Леонова Елена Николаевна

К.п.н., дочент, Тихоокеанский государственный университет, Хабаровск enleonova62@mail.ru

Гирина Ирина Геннадьевна

К.филол.н., дочент, Тихоокеанский государственный университет, Хабаровск

Аннотация: В данной статье анализируются способы передачи лингвокультурных особенностей текста английской сказки при переводе. Языковая картина мира народа отражает его культурную картину мира, культурные особенности народа отражаются в созданных им текстах. К лингвокультурным особенностям изучаемого текста относятся мифологизированные языковые единицы, символы, безэквивалентная лексика, стилистический уклад языков. При анализе перевода обращается особое внимание на передачу диалектизмов, просторечия, эвфемизмов, на учет различий в объёме значения лексических единиц, а также на выбор стратегии перевода.

Ключевые слова: лингвокультура, символ, эвфемизм, просторечие, стратегия перевода.

как ее антиномичность. «Антиномия понимается нами как единство двух противоположных, но одинаково хорошо обоснованных суждений в культуре». [1; с.16] Ученая указывает на наличие двух противоположных тенденций в ходе приобщения к культуре:

- социализации личности и одновременно ее индивидуализации.

- культура не зависит от общества и, в то же время, не может существовать вне общества;

- культура направлена на сохранение традиций, но не может существовать без инноваций.

Поэтому исследование взаимоотношения языка и культуры в процессе перевода становится одной из самых актуальных проблем в языкознании на протяжении XX и в начале XXI вB.

Немецкий философ Э. Кассирер выделяет следующие составляющие культуры: язык, миф, искусство, религия, история. Все эти компоненты в равной мере составляют национальный стержень любого сообщества. Э. Кассирер указывал на символический смысл национальной культуры, который зашифрован в самих ее компонентах: язык - это знаковая система, базирующаяся на символах; миф является рефлексией целого национального сообщества, в котором в символической форме отражаются 
все остальные культурные составляющие: искусство, религия, история. [2; 76] Миф - это отражение национального самосознания целого народа. Символический характер мифа заключается в персонификации абстрактных явлений, исторических событий, человеческих пороков и т.д. На более позднем этапе миф трансформировался в сказку.

Сказка является отражением не только народной культуры, но и народной мудрости, идеалов, норм поведения, психологического уклада и. даже морали, присущей данному народу.

Следует отметить, что взаимопонимание может возникнуть при адаптации менталитета представителя исходного языка для языка перевода. В этой связи роль переводчика трудно переоценить.

Поскольку в наше время целевая аудитория читателей сказок - это дети и их родители, читающие им сказки, то, по меткому замечанию М. Шумановой, необходимо найти такой способ перевода, чтобы сказка звучала так же естественно, как голос матери, читающей сказку. [3]

При исследовании художественного перевода английской сказки на русский язык возникает проблема адекватности передачи языковых средств в процессе межкультурного взаимодействия. И.Я. Рецкер,[4] С.Г. ТерМинасова, [5] А.Д. Швейцер [6] указывали на различные механизмы взаимодействия языка и культуры. Контакт культур осложняется в процессе восприятия текстов с культурно-маркированной лексикой, поскольку адекватное восприятие затрудняется в связи с отсутствием эквивалентов в языке перевода. Расхождения в языковом мышлении проявляются в ощущении избыточности или недостаточности форм выражения одного и того же понятия по сравнению с родным языком. В этой связи перевод является не только способом передачи смыслов, но и ключом для вхождения в иную культуру. Переводчику не достаточно простого понимания текста с культурно маркированными компонентами, но и необходимость выбора способов перевода для наиболее адекватной передачи культурных смыслов, характерных для исходного языка.

Ю. Найда, говоря об эквивалентности в переводе, разделяет этот феномен на два вида: формальная эквивалентность и динамическая эквивалентность. Согласно концепции перевода, разработанной ученым, формальная эквивалентность «ориентирована на оригинал», в то время как динамическая - на «реакцию рецептора», т.е. оказывает равное воздействие на рецепиентов как перевода, так и оригинала. [7; 24] Но в результате маркированных текстов ученый предлагал придерживаться путей достижения динамической эквивалентности, отрицая при этом наличие в текстах перевода чуждых культурно-этнических фактов и в результате стремления к достижению динамической эквивалентности теряется национальный колорит исходного текста.

Для перевода народных сказок необходимо придерживаться двух диаметрально противоположных переводческих стратегий: форенизации и доместикации «профессиональное маневрирование переводчика между ними.» Стратегия «доместикации» определяется как способ перевода, при котором происходит «замена иностранных элементов в тексте на элементы принимающей культуры», а противоположная ей форенизация, т. е «сохранение национального компонента и колорита при переводе.»[7; 14]

Определяя объект исследования лингвокультурологии как «исследование взаимодействия языка, который есть транслятор культурной информации, культуры с ее установками и преференциями и человека, который создает эту культуру, пользуясь языком», В.Е. Маслова выделяет сразу целый ряд ее предметов:

1. безэквивалентная лексика и лакуны;

2. мифологизированные языковые единицы: архетипы и мифологемы, обряды и поверья, ритуалы и обычаи, закрепленные в языке;

3. паремиологический фонд языка;

4. фразеологический фонд языка;

5. эталоны, стереотипы, символы;

6. метафоры и образы языка;

7. стилистический уклад языков;

8. речевое поведение;

9. область речевого этикета. [1; 24]

Народные сказки долгое время существовали только в устной форме, передаваясь из поколения в поколение. Впервые собрал и опубликовал два тома английских народных сказок Джозеф Джейкобс (1854-1916). Он подчеркивает, что английские сказки существовали в устной форме до конца XIX в. [8] Ему удалось собрать около 140 сказок, что говорит об их небольшой распространенности. Среди литераторов, которые собирали народные сказки, также известны Дина М. Малок, Эндрю Лэнг, Роджер Грин и Кэтлин Фойл.

Относительно позднее появление литературных вариантов народных сказок связано с некоторыми запретами, существовавших в обществе. Один из запретов был связан с развитием образования, стандарты которого требовали чтения серьезных рассказов, а не вымышленных историй. Поэтому сказки, в которых присутствовали исторические элементы и деятели, были сохранены в большей мере. Другой запрет на литературную обработку сказок был связан с Библейским движением (XIV в.), которое истребляло язычников и все, что принадлежало языческой вере. Сказки подвергались суровой критике и не были допущены до печати, продолжая существо- 
вать в устной форме до XIX в.

С. Никонова отмечает, что интерес к фольклору прослеживается еще в самых ранних, написанных в период Средневековья произведениях английских авторов (Thomas Malory, Morte Darthur, 1470). Фольклорные мотивы отражены также в поэзии Филиппа Сиднея (Philip Sydney, 1554-1586) и Эдмунда Спенсера (Edmund Spenser, 1552-1599). Важный элемент сказочной фантастики и следы фольклора можно обнаружить и в пьесах Вильяма Шекспира (A Midsummer Night's Dream, 1595; The Winter's Tale, 1610; The Tempest, 1612). Многие сказочные персонажи встречаются в произведениях XVI - XVII веков от Бена Джонсона (Ben Johnson, 1573 - 1637) до Драйдена (John Draiden, 1631 - 1709) [9, c.3].

Однако попытки популяризировать фольклорные сказки в Англии не были успешными, так как литераторы встретились с серьезным сопротивлением фольклористов, которых волновало сохранение лингво-этнографической подлинности этих литературно-исторических памятников. Тексты нуждались в обработке в соответствии с нормами современного английского языка и общепринятого диалекта. В некоторых случаях появлялась необходимость менять разные элементы сюжета, и это вызывало конфликт между фольклористами и литераторами [9; с.11]. Несмотря на все препятствия, были собрано множество народных сказок, которые сохранили особый колорит и стиль, а также стали очень популярными среди читателей.

Рассмотрим английскую народную сказку Том Тит Тот (Tom Tit Tot) и ее перевод, выполненный Н. Шерешевской. [10]. Обратившись к истории Англии, можно с большой долей уверенности утверждать, что анализируемая сказка появилась на рубеже XV - XVI веков. Именно в это время Англия во что бы то ни стало стремилась восстановить, подорванную многочисленными войнами экономику, а для этого надо было сделать конкурентноспособным производство шерсти, направляемой на экспорт. Для того чтобы превзойти своего конкурента в этой области, Голландию, англичане решили поставлять не сырье, а пряжу. Поскольку прядильные станки появились века спустя, единственный способ прясть пряжу был - засадить всех женщин королевства от мала до велика, не взирая на социальное положение, за прялки. Отсюда, женщины, производительность труда которых была высока, считались наиболее добродетельными и завидными невестами. К сожалению, подобный страноведческий комментарий отсутствует в сборнике переводных сказок, затрудняя понимание того, почему король посватался к простой девушке, едва узнав, что она искусная пряха.

Сюжет короткой волшебной сказки Tom Tit Tot, cxoжий с сюжетом немецкой сказки 'Rumplestiltskin' в собра- нии сказок братьев Гримм, заключается в том, что дочь съела пять пирогов, испеченных матерью на ужин, не оставив ни крошки. Мать, сидя за прялкой, пела об этом ('My darter ha' ate five, five pies today'), её пение услышал проходящий мимо король, но не мог разобрать слов и попросил её повторить. Женщина, устыдившись недостойного поведения дочери, изменила слова и спела о том, что её дочь спряла пять мотков пряжи ('My darter ha' spun five, five skeins today'). Матери было необходимо сохранить репутацию семьи, поскольку трудолюбие - важнейшая ценность протестантской культуры, а умение прясть считалось признаком трудолюбия девушки, при этом лень и неумеренность резко осуждались. Король был восхищён трудолюбием девушки и решил взять её в жены на том условии, что она будет жить в роскоши одиннадцать месяцев, а весь последний двенадцатый месяц года будет прясть по пять мотков пряжи в день. Если она не справится с этой задачей, то будет казнена. Дочь, которая не умела прясть, прожила в королевском дворце одиннадцать месяцев, а потом, чтобы избежать казни, заключила сделку с нечистой силой. В качестве платы она должна была угадать имя чертёнка, который ей помогал, иначе он бы забрал её с собой. В последний день месяца ей по счастливой случайности удалось узнать имя чертёнка - Tom Tit Tot, и она была спасена.

В сюжете сказки есть мотивы, стереотипы и символы, характерные как для европейских сказок вообще, так и для английских народных сказок, в частности. Это, например, типичные ситуации, когда герой должен отгадать загадку или угадать имя, чтобы спасти свою жизнь, когда простолюдинка выходит замуж за принца, когда герой прибегает к помощи потусторонних сил. Все эти мотивы получили своё отражение в данной сказке. Также можно отметить числовой символизм. Мать испекла пять пирогов. Число 5 - это символ человека, его пяти чувств, он также связан с символикой руки (пять пальцев). Девушка прожила в королевском дворце 12 месяцев. Число 12 означает космический порядок и завершенность.

В сказке представлены такие национально-культурные особенности как стилистический уклад языков, использование диалектизмов, просторечия и эвфемизмов. Поскольку сказка рассказывается на Саффолкском диалекте, это отражено в тексте, например, darter вместо daughter, My darter ha' ate вместо My daughter has eaten. Также графически отражено использование просторечных форм 'еm, вместо them, о' вместо of, ain't вместо isn't или aren't.

Так, в оригинальной версии сказки герои в своей речи используют диалектизмы и просторечные грамматические формы: «Darter, s says she, «put you them there pies on the shelf, and leave 'em there a little, and they'll come again. В переводе этот просторечный язык не сохраняется: - 
Поставь-ка, доченька, паштеты вон на ту полку! Пусть полежат себе там немножко, может еще подойдут. Диалектное darter можно перевести русским диалектным доца, а put you them there pies on the shelf, как поставь ты их, эти пироги на полку. В данном случае в переводе теряется народный говор, придающий сказке национальный колорит, но поскольку сказки рассчитаны, в основном, на детскую аудиторию, то перевод просторечного говора будет избыточным. Поэтому литературный перевод можно считать в этом случае адекватным. При этом частица -ка (поставь-ка), уменьшительно-ласкательный суффикс (доченька), наречие «немножко» вместо «немного» придают речи разговорный оттенок. В данном контексте вызывает вопросы лексическая замена при переводе слова pies (naumemы, а не пироги). Дело, вероятно, в том, что «паштетом» в Европе назывался круглый пирог с начинкой из фарша (нем. Pastete «паштет», «пирожок»). Однако, данное значение слова «паштет» читателю не известно, а пирог (хлеб) является одним из христианских символов, понятным и для русского читателя. В данном случае переводчица прибегла к форенизирующей, а не к доместикационной стратегии перевода.

Переводческие трудности связаны с различиями в объеме значения слов. Завязка сказки построена на игре слов: They'll come again, (может еще подойдут) говорит мама о пирогах. Дочь ее понимает по-своему: "Well, if they'll come again, I'll eat 'em now." («Что ж, если еще подойдут, так эти я сейчас съем»). В данном контексте выражение come again может иметь двоякий смысл: «прийти куда-либо, вновь появиться» и разговорное «стать мягче». В переводе эта игра слов передается фразой «они подойдут», при этом игра слов полностью сохраняется, а, следовательно, сохраняется и завязка, на которой строится сюжет. Но в русском языке «подходить» может только тесто, печеные пироги подходить не могут, они могут «отходить». Но тогда не сохраняется игра слов. Поэтому переводчик принимает правильное решение, наделяя русское выражение новой контекстуальной семантикой, и в данном случае можно говорить о доместикационной стратегии перевода.
Как уже констатировалось, переводчику необходимо владеть не только языком перевода, но и иметь фоновые знания о культуре страны, с языка которой осуществляется перевод. В этой связи можно привести пример перевода эвфемизмов. Возьмем, в частности, предложение:

She upped and oped it, and what should she see but $\boldsymbol{a}$ small little black thing with a long tail.

В этом предложении впервые упоминается о чертенке, который старался во что бы то ни стало завладеть душой молодой королевы. В английской культуре, особенно в средние века, когда 100\% населения страны были верующими, было запрещено упоминать имена не только святых. но и нечистой силы. Чтобы оградить себя от несчастий, англичане использовали эвфемизмы. Таким образом, выражение a small little black thing является эвфемизмом, который употребляется вместо слова devil, что видно из контекста. Поскольку в нашей культуре этого запрета нет, то перевод Н. Шерешевской можно считать адекватным.

Она встала и быстро открыла дверь. И что же она увидела? Крошечного черного бесенка с длинным хвостом.

Переводческой удачей можно считать и перевод предложения, содержащего восклицание короля, когда он услышал о пяти мотках пряжи, которые спряла девушка за день:

«Stars o' mine!» said the king, как - Бог мой! - воскликнул король.

В данном примере, как и в предыдущем, переводчик игнорирует эвфемизмы подлинника, и, в результате доместикации, мы получаем адекватный перевод, понятный русскоязычному реципиенту.

Подводя итоги, можно сделать вывод о том, что переводчику в целом удалось достичь адекватности при передаче лингвокультурных особенностей сказки, при этом применялась преимущественно доместикационная стратегия для того чтобы сделать текст понятным русскоязычной аудитории.

ЛИТЕРАТУРА

1. Маслова В.А. Лингвокультурология: Учеб. пособие для студ. высш. учеб, заведений. — М.: Издательский центр «Академия», 2001. — 208с.

2. Кассирер, Э. Избранное. Опыт о человеке / Э. Кассирер; - М.: Гардарика, 1998. - 784 с.

3. Шуманова М. Национально-культурная информация в сказке и ее сохранения при переводе. Болгарская русистика, 2005/ 3-4, с.68-80.

4. Рецкер Я.И. Теория перевода и переводческая практика. М.: Р. Валент, 2007. 244 с.

5. Тер-Минасова С.Г. Язык и межкультурная коммуникация. М.: «Слово», 2000, 176с.

6. Швейцер А.Д. Теория перевода: статус, проблемы, аспекты. М.: Наука , 1988. 214с.

7. Найда Ю. К науке переводить // Вопросы теории перевода в зарубежной лингвистике / Под общ. ред. В.Н. Комиссарова. - М.: Высшая школа, 1978. C. $114-137$

8. Лукин Д.С. Лингвокультурные особенности перевода средств выразительности с языка оригинала на русский язык на материале произведений 
Дж. Роулинг «Гарри Поттер». Автореферат диссертации на соискание ученой степени кандидата филологических наук. 9. J. Jacobs. English fairy tales. G.P. Putnam's sons. New York, London, 1892.

10. Английская литературная сказка (Сборник), М.: Изд-во Терра-Книжный Клуб, 2017. 320 с.

11. Английские народные сказки. Изд-во Речь, 2017. 243 с.

(c) Леонова Елена Николаевна (enleonova62@mail.ru), Гирина Ирина Геннадьевна.

Журнал «Современная наука: актуальные проблемы теории и практики»

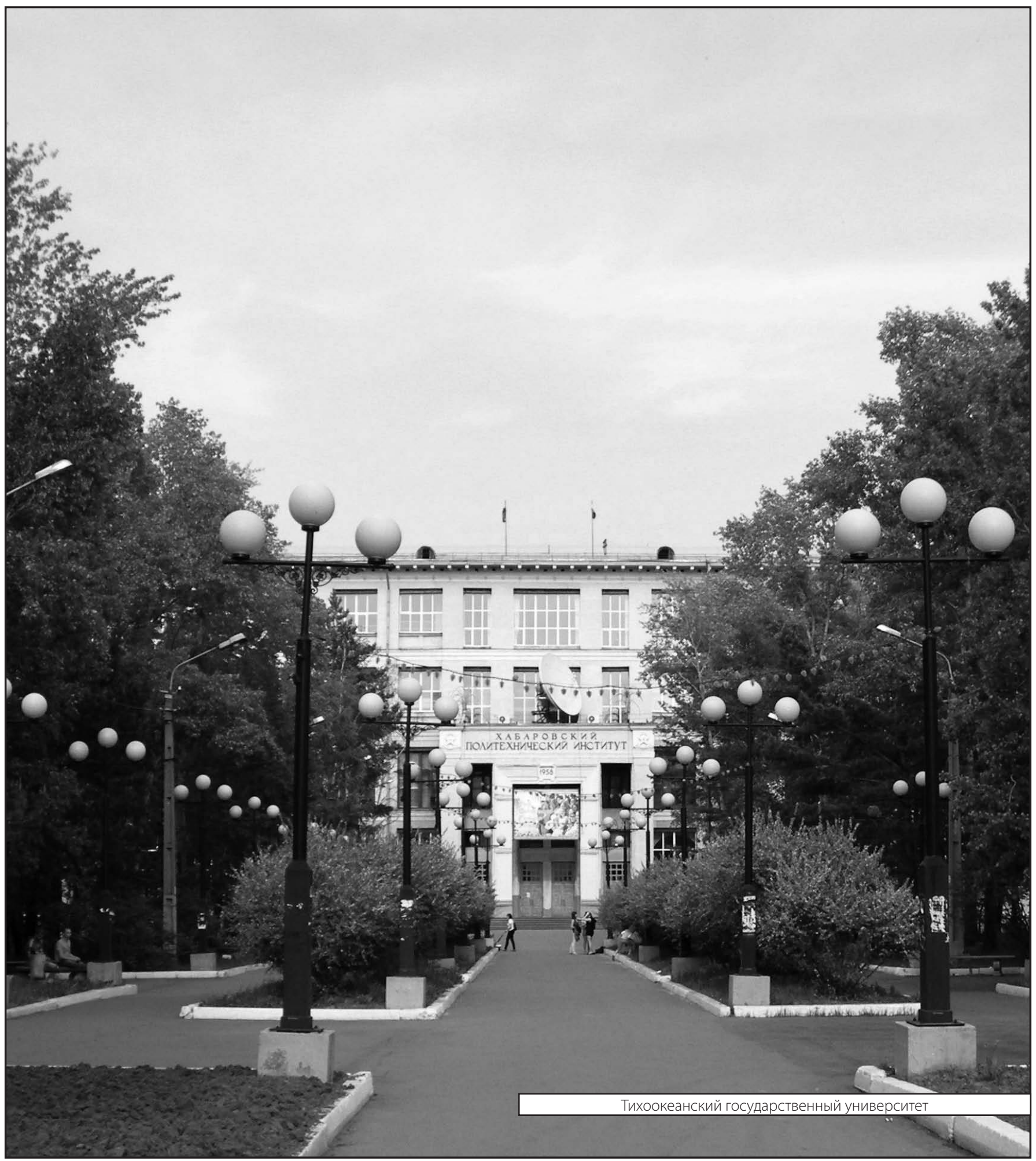

